\title{
Evaluating the Knowledge Management Practices of Construction Firms by Using Importance-Comparative Performance Analysis Maps
}

\author{
Serdar Kale ${ }^{1}$ and Erkan A. Karaman ${ }^{2}$
}

\begin{abstract}
The emergence of the effective management of knowledge resources as a key factor in gaining and sustaining competitive advantage presents new challenges to construction firms. Evaluating knowledge management practices is considered one of the most important challenges facing firms in today's business environment. This paper proposes a model for evaluating the knowledge management practices of construction firms. The proposed model incorporates knowledge management concepts and multilayer perceptron (MLP) neural networks to construct an importance-comparative performance analysis (ICPA) map, a simple visual tool that can provide powerful diagnostic information to executives of construction firms. The model evaluates a firm's knowledge management practices, identifies its competitive advantages and disadvantages in each knowledge management practice, and sets priorities for managerial actions to improve knowledge management practices. A real-world case study was conducted by administering a survey to 105 construction firms operating in Turkey and is presented to illustrate the implementation and utility of the proposed model. The case study findings provided preliminary support for the validity of the proposed model. DOI: 10.1061/(ASCE)CO.1943-7862.0000369. () 2011 American Society of Civil Engineers.
\end{abstract}

CE Database subject headings: Organizations; Knowledge-based systems; Construction industry; Neural networks; Construction companies; Performance characteristics.

Author keywords: Organizations; Knowledge management; Construction industry; Artificial neural networks; Performance; Construction firm.

\section{Introduction}

The knowledge-based view of the firm (Spender 1996; Grant 1996) constitutes the latest milestone in the evolution of the concept of competitive advantage. It proposes that gaining and sustaining competitive advantage in today's business environment depends significantly on knowledge resources. Managing knowledge resources presents new challenges to the firms regardless of their size, type, or industry. One of these new challenges is evaluating firms' knowledge management practices, which is considered an essential and inseparable part of managing knowledge resources (Marr and Spender 2004). Several research studies (e.g., Hsieh et al. 2009; Wen 2009) have proposed a number of performance measurement models to evaluate firms' knowledge management practices.

The research presented in this paper proposes a simple but powerful performance measurement model to evaluate knowledge management practices in construction firms (Fig. 1). The proposed framework differs from previously proposed models on three counts. First, it includes the competitive perspective in performance evaluation. A succinct review of performance measurement models (e.g., Kululanga and McCaffer 2001; Arif et al. 2009) developed to

\footnotetext{
${ }^{1}$ Associate Professor, Dept. of Architecture, Izmir Institute of Technology, Urla, Izmir 35430, Turkey (corresponding author). E-mail: serdarkale@iyte.edu.tr

${ }^{2}$ Research Assistant, Dept. of Civil Engineering, Balikesir Univ., Balikesir 10145, Turkey. E-mail: eakaraman@balikesir.edu.tr

Note. This manuscript was submitted on February 24, 2010; approved on February 8, 2011; published online on February 10, 2011. Discussion period open until May 1, 2012; separate discussions must be submitted for individual papers. This paper is part of the Journal of Construction Engineering and Management, Vol. 137, No. 12, December 1, 2011. CASCE, ISSN 0733-9364/2011/12-1142-1152/\$25.00
}

evaluate the knowledge management practices of construction firms reveals that the competitive environment in which construction firms operate was almost always ignored in formulating these models. This exclusion is one of the major limitations of performance evaluation models of knowledge management practices in construction firms. Chen et al. (2009) argue that inclusion of the competitive environment in evaluating knowledge management presents important benefits such as ability to identify, understand, and adopt best practices, and the opportunity to establish standards against which processes, services, and products can be compared and consequently be improved. Second, it uses multilayer perceptron (MLP) neural networks to model performance evaluation. Chen and Chen's (2006) comprehensive review of performance measurement models that evaluate knowledge management practices concludes with the suggestion that artificial intelligence techniques should be used in future research. This suggestion has not been considered in any subsequently proposed performance evaluation model (e.g., Hsieh et al. 2009; Wen 2009). Third, it uses importance-comparative performance analysis (ICPA) maps (Martilla and James 1977; Deng and Pei 2009) to evaluate knowledge management practices. An ICPA map is a visual tool that has been predominantly used in the marketing literature for continuous improvements in processes and the performance of firms. Yet, it has not been used in the construction management literature or for evaluating knowledge management practices.

The main objectives of the proposed model are (1) to provide executives of construction firms an internal reporting tool that can evaluate their firm's knowledge management practices, (2) to assist executives of construction firms in identifying their firm's competitive advantages and disadvantages in each knowledge management practice, and (3) to set priorities for managerial actions in those knowledge management practices that need improvement. 


\section{Selecting knowledge management practices} for evaluation

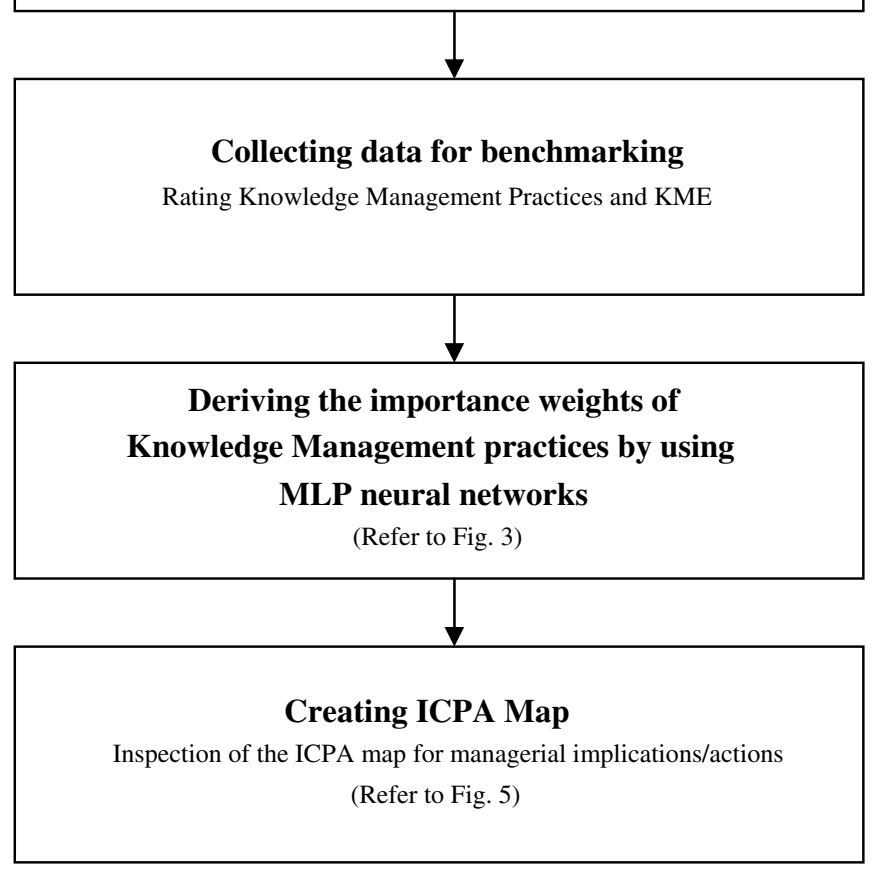

Fig. 1. Model for evaluating the knowledge management practices of construction firms

The basic concepts of knowledge management and MLP neural networks set used in developing the model are presented in the following two sections.

\section{Knowledge Management Practices and Construction Firms}

The increasing importance of knowledge as a key resource in gaining competitive advantage in today's construction business environment, coupled with the well-known characteristics of the construction industry (i.e., project-based, knowledge-intensive, demand-driven, and fragmented), present new challenges to construction firms. Several knowledge management models, such as the cross-sectoral learning in the virtual enterprise (CLEVER) (Kamara et al. 2002), improving management performance through knowledge transformation (IMPaKT) (Robinson et al. 2004); start-up-takeoff-expansion-progressive-sustainability (STEPS) (Robinson et al. 2005), and knowledge value adding model (KVAM) (Yu et al. 2009), have been developed to assist construction firms in addressing these challenges. They have provided important insight into the concept of knowledge management and how it can be measured and used for improvement in construction firms.

Over the years, a number of research studies have revealed that construction firms in the United Kingdom (Al-Ghassani et al. 2004; Carrillo et al. 2004; Robinson et al. 2005), the United States (Carrillo and Chinowsky 2006), Hong Kong (Fong and Chu 2006), and Turkey (Kivrak et al. 2008) have all encountered barriers in implementing knowledge management in their firms. The major barriers to implementing knowledge management that emerged from these studies include inadequate understanding of knowledge management, lack of management support, inappropriate information and communication technology (ICT), organizational culture and structure, difficulty in communicating the benefits of knowledge management to employees, lack of resources, difficulty measuring the value added, and a narrow organizational focus on knowledge management. Recently, Chinowsky and Carrillo (2008) suggested that construction firms should adopt a strategic approach to knowledge management to overcome these barriers. Such an approach requires (1) linking knowledge management to competitive advantage and (2) adopting a holistic approach to knowledge management (Chinowsky and Carrillo 2008). A performance evaluation model for knowledge management practices that is built on these premises can assist construction firms in overcoming these barriers. A major step in developing such a model is a succinct review of the concept of knowledge management to identify the major themes that have emerged from knowledge management studies.

Knowledge management refers to the creation and subsequent management of an environment that encourages knowledge to be created, shared, learned, and organized for the benefit of the firm (Sarrafzadeh et al. 2006). The earliest research studies on knowledge management have been predominantly driven by a technical perspective [i.e., information systems (IS)] (Hansen et al. 1999) that primarily focuses on technical aspects (i.e., processes, tasks, and technology) of knowledge management. Subsequent recent research studies have shifted their focus from technical aspects to social aspects (i.e., relationships among people, attributes of people reward systems, and authority structures) (Hansen et al. 1999). Contemporary research studies on knowledge management such as those by Lee and Choi (2003), Chuang (2004), Carrillo and Chinowsky (2006), Lin (2007), and Javernick-Will and Scott (2010) build on a synthesis of social and technical perspectives. The central themes in these research studies have been (1) defining the concept of knowledge management effectiveness (KME) and (2) identifying the primary knowledge management practices that influence KME in firms. The concept of KME can be better understood by defining the term effectiveness. The term effectiveness refers to the degree to which a process or practice realizes its goals (Daft 1995). This definition implies that the goals of knowledge management should also be defined. Wiig (1997) adopts a strategic approach to knowledge management by arguing that the primary goal of knowledge management is to create and sustain competitive advantage. Creating and sustaining competitive advantage means that a firm outperforms its rivals on some criteria, such as (1) financial perspective_- profitability and return on investment; (2) process perspective-continuous improvement, streamline internal processes, introducing innovative construction methods and contracting services, and responsiveness to technological changes; (3) market perspective-market share, growth in market share, identifying opportunities for new construction projects, and markets; or (4) customer/client perspective-increasing client satisfaction, and gaining repeat business.

Identifying the primary knowledge management practices that influence KME has been another central research issue in contemporary research studies. The primary knowledge management practices that emerged from previous research studies include (e.g., Gold et al. 2001; Chuang 2004): (1) the knowledge management process and (2) knowledge management enablers.

Knowledge management processes represent the basic operations of knowledge (Lee and Choi 2003). Different models have been set forth to define the knowledge management process (e.g., Wiig 1993; Nonaka and Takeuchi 1994; Gold et al. 2001). A succinct review of these models reveals that they vary in their scope and level of detail. The model proposed in this paper uses 
Gold et al.'s (2001) knowledge management process model because their model is sufficiently broad to permit a complete analysis of knowledge management processes and commonly used in knowledge management studies (Lin 2007). Gold et al.'s (2001) knowledge management process model involves four subprocesses: the acquisition, conversion, application, and protection of knowledge.

Knowledge acquisition process involves activities for searching and capturing entirely new knowledge or using existing knowledge to create new knowledge out of existing knowledge (Inkpen 1996). Three primary processes of knowledge acquisition for a construction firm are (1) searching the firm's internal environment (e.g., the firm's existing knowledge, and employees' knowledge and experiences) and its external environment (e.g., government agencies, competitors, research institutions, and clients/customers), (2) monitoring its performance related to its operations and activities, and (3) facilitating intrafirm and interfirm collaboration. Knowledge conversion refers to a process that is oriented toward making existing knowledge useful. It involves organizing, structuring, integrating, and storing the firm's acquired knowledge or created knowledge in ways that make it formalized and easier for interested parties (i.e., groups and individuals) to access and use. It also involves combining and integrating the specialized knowledge that individuals possess, the knowledge that resides in different parts of the firm, and the knowledge that resides in different systems within the firm. Combining and integrating knowledge can reduce redundancy, improve representational consistency, and enhance efficiency by eliminating excess volume. Knowledge application refers to the process that involves the utilization of knowledge for improving efficiency and effectiveness in activities and operations. Such a process can produce significant beneficial effects for a construction firm. Knowledge application involves retrieving, sharing, and using knowledge for adjusting strategic direction, solving new problems, and improving processes, all of which, in turn, create value for the firm. Knowledge protection involves protecting knowledge from inappropriate use, illegal use, and theft. A firm's knowledge, like any other resource, can be a source of competitive advantage as long as its rareness and inimitability are preserved. Table 1 presents examples of indicators for evaluating knowledge management processes.
Knowledge management enablers are the organizational mechanisms that stimulate the creation and development of knowledge within an organization and also facilitate the creation, conversion, application, and protection of that knowledge (Lee and Choi 2003). These mechanisms constitute the infrastructure that is necessary for the organization to increase the efficiency of knowledge management processes. Different schemes have been proposed for classifying knowledge management enablers (e.g., Carrillo 2004; Javernick-Will and Levitt 2010). The research presented uses Chuang's (2004) classification scheme and decomposes knowledge management enablers into two groups: technical knowledge management enablers and social knowledge management enablers.

Technical knowledge enablers include a number of ICTs, such as document management systems, information management systems, searching and indexing systems, expert systems, and communication and collaborative systems. Such systems can be used by the firm to support and enhance the acquisition, conversion, application, and protection of organizational knowledge. Table 2 presents examples of ICTs that can be used by construction firms to support their knowledge management processes. Some of the ICTs can be used simultaneously to support more than one knowledge management process.

Social knowledge management enablers refer to the sum of the actual and potential resources available that derive from the relationships and interactions of social entities (i.e., individuals, departments, and firms) (Nahapiet and Ghoshal 1998). They can be decomposed into two components (Chuang 2004): (1) organizational culture and (2) organizational structure. Organizational culture includes a set of values, norms, beliefs, expectations, and assumptions that are widely shared in an organization (Huber 2001). It exists in three different levels: (1) assumptions (i.e., unconscious, taken-for-granted beliefs, perceptions, thoughts, and feelings), (2) values (i.e., the organization's goals, ideals, and philosophies), and (3) artifacts (i.e., language, stories, myths, rituals, ceremonies art, attire, and layout) (Schein 1985). In knowledge management studies, organizational culture has been conceptualized in values (Alavi et al. 2006) primarily because organizational values are easier to establish than other levels (e.g., organizational artifacts or organizational assumptions), which have an abstract or vague nature and are difficult to conceptualize and delineate.

Table 1. Sample Items for Measuring Knowledge Management Processes

\begin{tabular}{lr}
\hline $\begin{array}{l}\text { Knowledge management } \\
\text { process }\end{array}$ & Activities \\
\hline
\end{tabular}

Knowledge acquisition process Creating, searching, collaborating

Knowledge conversion process $\quad$ Organizing, storing, integrating, combining

Knowledge application process $\quad$ Retrieving, sharing

Knowledge protection process $\quad$ Securing
My firm is able to

(1) use feedback from projects to improve subsequent projects,

(2) generate new knowledge from existing knowledge, and

(3) acquire knowledge about its clients

My firm is able to

(1) transfer organizational knowledge to individuals,

(2) absorb knowledge from individuals into the firm, and

(3) integrate different sources and types of knowledge

My firm is able to

(1) apply knowledge learned from mistakes,

(2) take advantage of new knowledge, and

(3) match sources of knowledge to problems and challenges

My firm is able to

(1) protect knowledge from inappropriate use inside the firm,

(2) protect knowledge from theft from outside the firm, and

(3) restrict access to specific sources of knowledge

\footnotetext{
a Sources: Gold et al. 2001; Lee and Choi 2003.
} 


\begin{tabular}{|c|c|c|c|c|c|}
\hline \multirow[b]{2}{*}{$\begin{array}{l}\text { Knowledge } \\
\text { management } \\
\text { enablers }\end{array}$} & & \multicolumn{4}{|c|}{ Knowledge management processes } \\
\hline & & $\begin{array}{l}\text { Knowledge } \\
\text { acquistion } \\
\text { (searching, } \\
\text { collaborating, } \\
\text { creating) }\end{array}$ & $\begin{array}{c}\text { Knowledge } \\
\text { conversion } \\
\text { (organizing, storing, } \\
\text { integrating, } \\
\text { combining) }\end{array}$ & $\begin{array}{l}\text { Knowledge application } \\
\text { (retrieving, sharing) }\end{array}$ & $\begin{array}{l}\text { Knowledge protection } \\
\text { (securing) }\end{array}$ \\
\hline $\begin{array}{l}\text { Technical KM } \\
\text { enablers }\end{array}$ & $\begin{array}{l}\text { Information and } \\
\text { communication } \\
\text { technology }\end{array}$ & $\begin{array}{l}\text { Internet, intranet, } \\
\text { knowledge work } \\
\text { systems, knowledge } \\
\text { discovery tools, } \\
\text { concept/mind } \\
\text { mapping, electronic } \\
\text { community of } \\
\text { practices, and data } \\
\text { mining }\end{array}$ & $\begin{array}{l}\text { Corporate and } \\
\text { project databases, } \\
\text { knowledge entries, } \\
\text { artificial intelligence, } \\
\text { expert systems, and } \\
\text { indexing/searching } \\
\text { system }\end{array}$ & $\begin{array}{l}\text { Intranet, internet, } \\
\text { knowledge sharing boards, } \\
\text { newsgroup and web-based } \\
\text { discussions, enterprise } \\
\text { information portal, } \\
\text { groupware, and decision } \\
\text { support systems }\end{array}$ & $\begin{array}{l}\text { Firewall system and } \\
\text { information security } \\
\text { system for tracking and } \\
\text { restricting access }\end{array}$ \\
\hline \multirow[t]{2}{*}{$\begin{array}{l}\text { Social KM } \\
\text { enablers }\end{array}$} & $\begin{array}{l}\text { Organizational } \\
\text { structure }\end{array}$ & $\begin{array}{l}\text { Formal training, post } \\
\text { project reviews, } \\
\text { questionnaire } \\
\text { surveys, knowledge } \\
\text { audit collaboration } \\
\text { with clients, } \\
\text { subcontractors, and } \\
\text { supplies, and } \\
\text { performance } \\
\text { monitoring }\end{array}$ & $\begin{array}{l}\text { Procedures, rules and } \\
\text { processes, document } \\
\text { management system, } \\
\text { formal incentive } \\
\text { system, group } \\
\text { problem solving and } \\
\text { decision making, and } \\
\text { standardization } \\
\text { process }\end{array}$ & $\begin{array}{l}\text { Memoranda and letters, } \\
\text { technical support, on-the- } \\
\text { job training, internal } \\
\text { newsletters and circulars, } \\
\text { technical forums, } \\
\text { communities of practice, } \\
\text { mentoring, and storytelling }\end{array}$ & $\begin{array}{l}\text { Employee conduct rules, } \\
\text { formal rules, and } \\
\text { procedures for } \\
\text { protecting knowledge }\end{array}$ \\
\hline & $\begin{array}{l}\text { Organizational } \\
\text { culture }\end{array}$ & $\begin{array}{l}\text { Valuing openness } \\
\text { collaboration, and } \\
\text { trust for invention } \\
\text { and innovation }\end{array}$ & $\begin{array}{l}\text { Valuing integrating, } \\
\text { converting, and } \\
\text { distributing } \\
\text { knowledge }\end{array}$ & $\begin{array}{l}\text { Valuing learning, sharing, } \\
\text { and applying knowledge }\end{array}$ & $\begin{array}{l}\text { Valuing protecting and } \\
\text { securing knowledge }\end{array}$ \\
\hline
\end{tabular}

Note: Compiled from Egbu and Botterill 2002; Carrillo 2004; Fong and Kwok 2009; Javernick-Will and Levitt 2010.

Organizational values constitute the backbone of organizational culture, and they can encourage or impede the acquisition, conversion, application, and protection of knowledge. Communicating organizational values to employees is a vital process for constructing an organizational culture that supports knowledge management processes. Some examples of cultural mechanisms (e.g., valuing openness, trust, and collaboration) to enhance knowledge management activities in construction firms are presented in Table 2.

Organizational structure can be considered as a social architecture of the roles and flows of authority, work materials, information, and decision processes that make up an organization (Pennings 1992). It provides a social framework for the transformation of inputs (i.e., human, capital, physical, and knowledge resources) into outputs (i.e., contracting service and a constructed facility). This social framework formally shapes behaviors of social entities and acts as an information and knowledge filter that can limit what a social entity sees in the operating environment (Cortes et al. 2007). It also can influence how a social entity perceives and interprets the environment. Therefore, organizational structure can facilitate or inhibit knowledge management activities and, in turn, the effectiveness of knowledge management. Table 2 presents some examples of structural mechanisms that construction firms can use to facilitate knowledge management processes.

Previous research studies (e.g., Gold et al. 2001; Lee and Choi 2003; Chuang 2004; Ghosh and Scott 2006; Lin 2007) provide overwhelming empirical and anecdotal evidence that suggests that knowledge management practices are positively and significantly related to KME. The concept of KME was operationalized and measured from the process perspective in these studies.

\section{Multilayer Perceptron Neural Networks}

Artificial neural network models are powerful, flexible, and intuitive data analysis approaches for capturing and identifying the complex relationships between input/independent variables and output/ dependent variables (Haykin 1999). The most commonly used artificial neural network model is the MLP neural network model. MLP neural networks consist of (1) an input layer, (2) an output layer, and (3) one or more hidden layers (Fig. 2). Each layer comprises one or more neurons. A neuron is an information-processing unit that is fundamental to the operation of an MLP neural network. Each neuron is linked to the other neurons in neighboring layers by varying weight coefficients that represent the strength of these connections (Russell and Norvig 2003). A neuron receives input signals, processes those signals, and delivers a single output. The following tasks are performed by a neuron in processing its input signals: (1) receiving input signals from other neurons, (2) multiplying input signals by corresponding weights, (3) summing weighted input signals, (4) transforming the computed sum by a transfer function, and (5) sending the transformed sum to other neurons.

In mathematical terms, this process for neuron $j$ can be described by the following equations (Russell and Norvig 2003):

$$
v_{j}=\sum_{i=1}^{n} w_{j i} x_{i}+b_{j}
$$




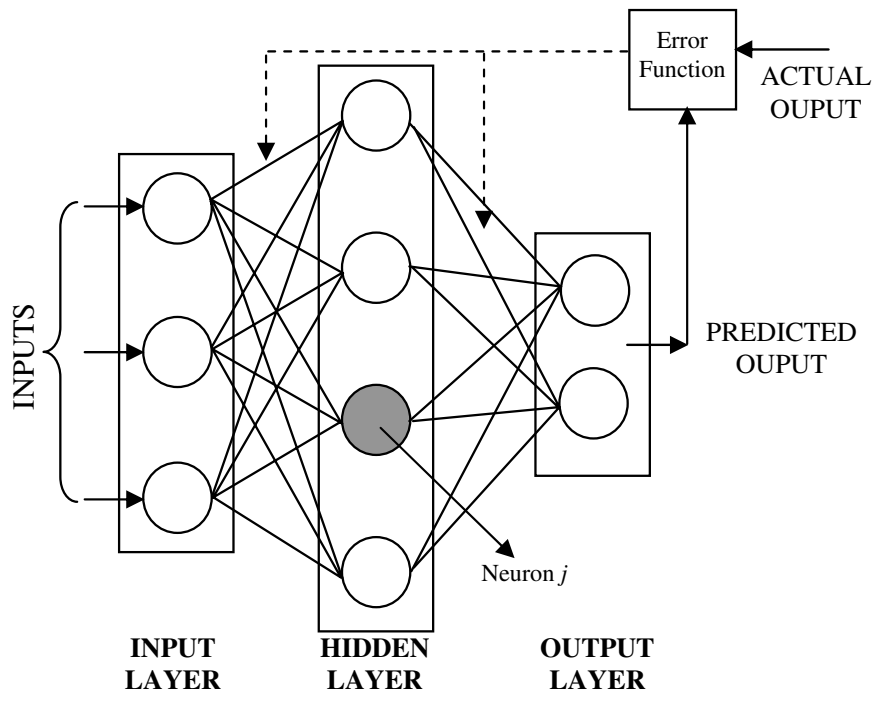

Fig. 2. Basic structure of MLP neural network

where $v_{j}=$ net input to neuron $j ; x_{i}=$ incoming signal from neuron $i$; $w_{j i}=$ weight associated with input from neuron $i ; n=$ number of neurons in preceding layer; and $b_{j}=$ bias associated with neuron $j$ and

$$
y_{j}=\Phi\left(v_{j}\right)
$$

where $y_{j}=$ output of neuron $j$ (also termed as the activation value of neuron $j$ ) and $\Phi=$ activation function to generate the outgoing signal of neuron $j$. Activation functions $(\Phi)$ can be linear or nonlinear such as an identity, hyperbolic tangent, logistic, exponential, sine, or Gaussian function.

Multilayer perceptron neural networks use supervised learning rather than unsupervised learning because output values are known, and input-output relationships are captured and identified on the basis of these known output values. The process of supervised learning involves five tasks as follows: (1) receiving input signals from the external environment, (2) propagating the input signals through the MLP neural network to the output layer, (3) computing the output of the MLP neural network, (4) comparing computed outputs with actual values by using an error function $(E)$, and (5) adjusting connection weights of neurons by using an optimization procedure to minimize differences between actual and computed outputs [Fig. 2]. Different supervised learning algorithms, such as the Levenberg-Marquardt (LM) algorithm, the conjugate gradient (CG) algorithm, the gradient descent (GD) algorithm, and the Broyden-Fletcher-Goldfarb-Shanno (BFGS) algorithm, can be used for minimizing the error function.

The connection weights in an MLP neural network model represent the relative importance of input(s)/independent variable (s) in predicting output(s)/dependent variable(s). The importance of an input variable $\left(W_{i}\right)$ in an MLP neural network model can be defined by Eq. (3) (Deng and Pei 2009)

$$
W_{i}=\frac{\sum_{h=1}^{H}\left(w_{h i}+w_{o h}\right)}{|H|} / \sum_{i=1}^{I} \frac{\sum_{h=1}^{H}\left(w_{h i}+w_{o h}\right)}{|H|}
$$

where $w_{h i}=$ connection weight from the $i$ th input variable $(i=$ $1, \ldots, I)$ to the $h$ th hidden node $(h=1, \ldots, H) ; w_{\text {oh }}=$ connection weight from the $h$ th hidden node to the oth output variable $(o=1, \ldots, O)$; and $|H|=$ cardinality of the hidden layer.
The primary challenges facing any researcher who uses MLP neural networks are identifying (1) the optimum network topology and (2) the criteria for evaluating the performance/fitness of the model. The network topology of an MLP neural network model is jointly defined by the number of (1) hidden layers and (2) neurons located in each hidden layer. No commonly accepted procedure exists for identifying the optimum number of hidden layers. Yet one hidden layer is commonly considered to be sufficient for capturing complexities in a data set and addressing practical problems (Deng and Pei 2009). No consensus exists on the procedure for identifying the number of neurons in a hidden layer. Trial and error, different rules of thumb, and search methods (e.g., Hecht-Nelson 1987; Lawrence and Fredrickson 1998) have been proposed in the literature for identifying the optimum number of neurons $\left(H_{\mathrm{opt}}\right)$ in a hidden layer. The most widely used approach is constructing lower and upper bounds for the number of neurons in a hidden layer and then searching for the optimum number of neurons within this range. The upper and lower bounds can be computed by formulas proposed by Hecht-Nelson (1987) and Lawrence and Fredrickson (1998), respectively. Hecht-Nelson (1987) proposes an upper bound for the number of neurons $\left(H_{\text {upper }}\right)$ in a single hidden layer as $2 I+1$, where $I$ is the number of input variables. Lawrence and Fredrickson (1998) propose a lower bound $\left(H_{\text {lower }}\right)$ of $(I+O) / 2$ where $O$ is the number of output variables.

The fitness/performance of MLP neural networks is commonly evaluated by using several statistical measures, such as (1) the correlation coefficient $(r),(2)$ the coefficient of determination $\left(R^{2}\right)$, (3) the root mean square error (RMSE), (4) the mean absolute error (MAE), and (5) the mean absolute percentage error (MAPE).

\section{Model Development}

The knowledge management evaluation model proposed in this paper builds on the concepts that have been set forth by knowledge management models (Gold et al. 2001; Lee and Choi 2003), MLP neural networks, and ICPA maps (Martilla and James 1977; Deng and Pei 2009). It involves a four-step procedure for evaluating the knowledge management practices of construction firms. These steps are as follows. Step 1: Selecting knowledge management practices for evaluation. Step 2: Rating knowledge management practices. Step 3: Deriving the importance weights of knowledge management practices. Step 4: Creating ICPA map (Fig. 1).

\section{Step 1: Selecting Knowledge Management Practices for Evaluation}

The first step involves selecting knowledge management practices $\left(C_{i}\right)$ that would be used during the benchmarking process. The section on knowledge management practices and construction firms reveals that seven knowledge management practices $\left(C_{i}\right.$, $i=1, \ldots, 7)$ influence a firm's KME, i.e., ICT $\left(C_{1}\right)$, organizational culture $\left(C_{2}\right)$, organizational structure $\left(C_{3}\right)$, knowledge acquisition $\left(C_{4}\right)$, knowledge conversion $\left(C_{5}\right)$, knowledge application $\left(C_{6}\right)$, and knowledge protection $\left(C_{7}\right)$.

\section{Step 2: Rating Knowledge Management Practices}

The second step involves rating the knowledge management practices $\left(C_{i}\right)$ of construction firms. A construction firm's knowledge management practices can be evaluated by using a two-stage process that involves the following: (1) developing a set of multi-item scales for measuring each knowledge management practice and (2) rating the construction firm's achievement on each item by using Likert-type scales. Using multi-item scales to measure each 
knowledge management practice enhances the reliability of the rating process. A construction firm's performance rating for each knowledge management practice $\left(R_{i}\right)$ is derived by summing up corresponding responses and calculating the mean. The questionnaire survey method can be used to collect data on construction firms' ratings of knowledge management practices.

\section{Step 3: Deriving the Importance Weights of Knowledge Management Practices}

The third step involves identifying the importance weights of each knowledge management practice $\left(W_{i}\right)$. These importance weights can be determined by using a stated approach (i.e., explicit approach) or a derived approach (i.e., implicit approach). The stated approach involves judging the importance of a knowledge management practice with linguistic variables such as low importance, moderate importance, and high importance. The stated approach involves a significant amount of subjectivity. Furthermore, it lacks in ability to differentiate between importance weights of evaluation criteria (Garver 2003). However, the derived approach involves the use of quantitative methods such as multiple regression analysis, correlation analysis, or artificial neural networks. The derived approach relies on scientific methods. It brings objectivity to the evaluation process and eliminates biases in the evaluation process (Garver 2003). Therefore, the derived approach is preferred to the stated approach. The process of implicitly deriving importance weights of knowledge management practices $\left(W_{i}\right)$ used in this study involves the use of MLP neural networks because MLP neural networks have advantages over statistical analysis methods such as multiple regression and partial correlation analysis that assume a linear relationship between model variables. Furthermore, parametric statistical analysis methods also require that the model variables meet the normality assumption, whereas MLP neural networks do not require such an assumption. Also in MLP neural network models, the relationships between model variables can be linear or nonlinear. These advantages of MLP neural networks make them a promising modeling approach in exploring managerial and organizational issues.

The input and output variables of the MLP neural network model used in this study are performance ratings of knowledge management practices $\left(R_{i}\right)$ and $\mathrm{KME}$ of the construction firms, respectively. The use of MLP neural networks to derive importance weights of knowledge management practices requires the assumption and presence of cause-effect relationships between independent/input variables $\left(R_{i}\right)$ and the dependent/output variable (KME). A succinct literature review (e.g., Gold et al. 2001; Lee and Choi 2003; Chuang 2004; Ghosh and Scott 2006; Lin 2007) points out that these requirements are met, i.e., knowledge management practices $\left(R_{i}\right)$ are positively related to the KME.

Knowledge management effectiveness of construction firms can similarly be measured by following the same procedure used in rating knowledge management practices $\left(R_{i}\right)$ of construction firms (i.e., developing multiitem scales and conducting questionnaire survey) (see Step 2).

\section{Step 4: Creating Importance-Comparative Performance Analysis Map}

The final step in evaluating knowledge management practices is selecting a construction firm to be benchmarked (i.e., case firm) and creating an ICPA map for each knowledge management practice $\left(C_{i}\right)$ for that construction firm. The ICPA map proposed by Deng and Pei (2009) is a modified version of the importanceperformance analysis map developed by Martilla and James (1977). It is a visual management tool that guides business executives to diagnose their weaknesses and identify their strengths in

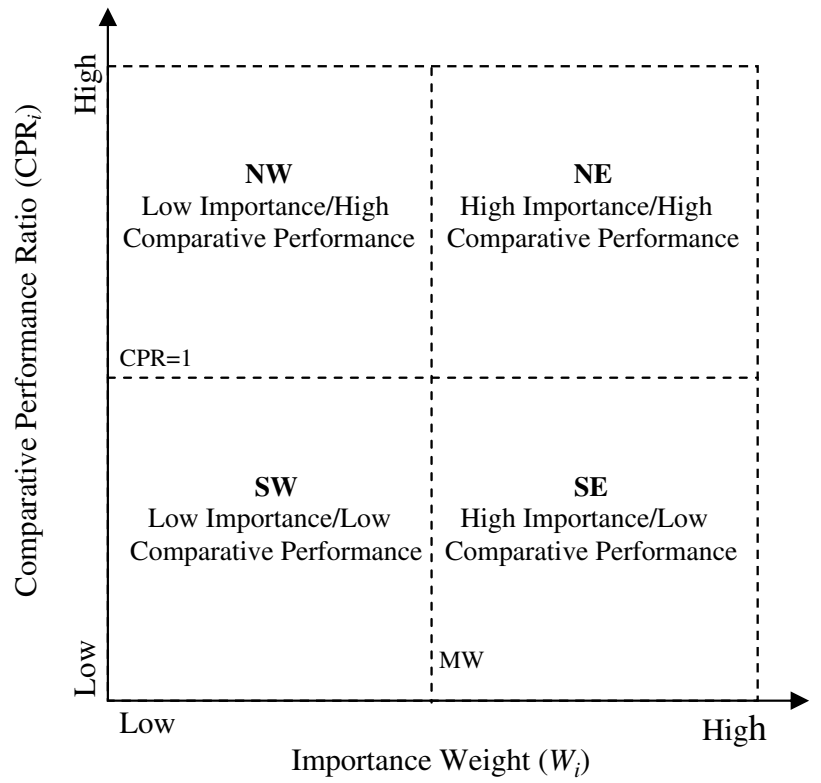

Fig. 3. ICPA map

knowledge practices and set priorities for managerial actions for those that need improvement. The ICPA map is a two-dimensional grid (Fig. 3). The horizontal axis indicates the importance weights $\left(W_{i}\right)$ of knowledge management practices, whereas the vertical axis represents the benchmarked firm's comparative performance ratios $\left(\mathrm{CPR}_{i}\right)$ of knowledge management practices.

Different comparative performance ratios can be used in constructing ICPA maps (Garver 2003). The comparative performance ratios used in this paper are calculated by dividing a benchmarked construction firm's performance rating $\left(R_{i}\right)$ for a given knowledge management practice $\left(C_{i}\right)$ by the average performance rating $\left(\mathrm{AvR}_{i}\right)$ for that knowledge management practice $C_{i}$ of all construction firms involved in the benchmarking process (Deng and Pei 2009).

$$
\mathrm{CPR}_{i}=\frac{R_{i}}{\mathrm{AvR}_{i}}
$$

Values of $\mathrm{CPR}_{i}$ that are greater than $1\left(\mathrm{CPR}_{i}>1\right)$ suggest that the benchmarked firm has a comparative advantage in the $i$ th knowledge management practice $\left(C_{i}\right)$. However, values of $\mathrm{CPR}_{i}$ that are less than $1\left(\mathrm{CPR}_{i}<1\right)$ suggest that the benchmarked firm has a comparative disadvantage in the $i$ th knowledge management practice $\left(C_{i}\right)$. Finally, when the value of $\mathrm{CPR}_{i}$ equals (1) $\left(\mathrm{CPR}_{i}=1\right)$, the benchmarked firm's performance rating for the $i$ th knowledge management practice equals the mean of all the benchmarked firms (i.e., industry average). The knowledge management practice $\left(C_{i}\right)$ that has a $\mathrm{CPR}_{i}$ ratio of 1 is said to generate competitive parity.

The ICPA map used to evaluate the knowledge management practices of construction firms consists of four quadrants (Fig. 3). Each of the quadrants is a combination of importance weights and comparative performance ratios of knowledge management practices. North East (NE) quadrant (high importance/high comparative performance) indicates knowledge management practices that can be a source of competitive advantage for the construction firm. Therefore, the construction firm should maintain its posture on each knowledge management practice located in this quadrant. South East (SE) quadrant (high importance/low comparative performance) shows the construction firm's major weaknesses in its 
knowledge management practices. Each knowledge management practice located in this quadrant needs immediate corrective action and has the highest priority for managerial action. Therefore, the construction firm should focus on improving each knowledge management practice located in this quadrant. South West (SW) quadrant (low importance/low comparative performance) holds knowledge management practices that need no immediate action. Each knowledge management practice located in this quadrant should be closely monitored because a change in the importance of a knowledge management practice in this quadrant can turn it to a major weakness for the construction firm. North West (NW) quadrant (low importance/high comparative performance ratio) points to knowledge management practices that a firm performs at a level that is above industry average but has low importance. Knowledge management practices located in NW quadrant should be reorganized or restructured to direct the firm's efforts toward the areas of importance that need improvement.

\section{Model Application}

The application of the benchmarking model proposed in the preceding section involves a two-stage process. The first stage involves collecting ratings of knowledge management practices $\left(R_{i}\right)$ and the $\mathrm{KME}$ of construction firms to derive the importance weights of knowledge management practices $\left(W_{i}\right)$. The second stage involves selecting a construction firm to be benchmarked and creating an ICPA map for the knowledge management practices of the selected construction firm.

\section{Sample and Data Collection}

A sample of 300 construction firms was identified by using directories and online databases to illustrate the application of the proposed model. Different formal and informal communication channels were used to reach these construction firms and request their participation in the survey. The final sample size decreased from 300 to 105 construction firms because some of the construction firms could not be contacted, and some others declined to participate or agreed to participate but failed to provide the requested information in a timely or complete manner. Table 3 presents the age and size profile of the construction firms surveyed.

Table 3. Demographic Characteristics of Surveyed Construction Firms $(N=105)$

\begin{tabular}{lcc}
\hline Size $^{\mathrm{a}}$ & Number of firms & Percentage $(\%)$ \\
\hline $20-40$ & 35 & 33 \\
$41-60$ & 7 & 7 \\
$61-100$ & 11 & 10 \\
$101-200$ & 15 & 14 \\
$201-500$ & 20 & 19 \\
Over 500 & 17 & 16 \\
\hline Firm age (years) & & \\
\hline $1-10$ & 18 & 17 \\
$11-20$ & 22 & 21 \\
$21-30$ & 26 & 25 \\
$31-40$ & 17 & 16 \\
$41-50$ & 15 & 14 \\
$51-60$ & 4 & 4 \\
$61-70$ & 3 & 3 \\
\hline
\end{tabular}

${ }^{\mathrm{a}}$ Number of full-time employees.
A questionnaire titled Knowledge Management Benchmarking Instrument (KMB-I) was prepared on the basis of the works of Gold et al. (2001) and Lee and Choi (2003). KMB-I includes a set of items for evaluating construction firms' knowledge management practices and their KME. KME was measured from processes perspective. The wording of the items was slightly modified to adapt them to context of the construction industry. Respondents were instructed to rate (i.e., $R_{i}$ and $\mathrm{KME}$ ) the extent to which they agree with each item on a 7-point Likert-type scale that ranged from 1 (strongly disagree) to 7 (strongly agree).

\section{Methods}

The reliability of the multi-item scales used to measure model variables (i.e., $R_{i}$ and $\mathrm{KME}$ ) is assessed by using the Cronbach alpha coefficients. The Cronbach alpha coefficients of all the multi-item scales (i.e., $R_{i}$ and KME) are above the threshold of 0.70 recommended by Nunnally (1978). They range from a high of 0.94 to a low of 0.84 . Therefore, it is concluded that the multi-item scales used to measure the model variables are reliable.

The MLP neural network model used to compute the importance weights of knowledge practices $\left(W_{i}\right)$ of construction firms consisted of (1) an input layer, (2) a hidden layer, and (3) an output layer. The importance weights of input variables (i.e., knowledge management practices) were computed by using the data mining module of the commercial software STATISTICA by StatSoft Inc. The sample $(N=105)$ was divided into two groups: $80 \%$ for training $\left(n_{\text {training }}=83\right)$ and $20 \%$ for testing $\left(n_{\text {testing }}=22\right)$. The optimum MLP neural network model was identified by using the automated network search feature of the STATISTICA software. This feature allows experimentation with various search combinations of (1) the number of neurons in the hidden layer and (2) the activation functions for hidden layer and output layer neurons. The parameters of the automated network search were set to (1) generate 500 MLP neural networks, (2) retain the best five MLP neural networks for further analysis, (3) vary number of neurons in the hidden layer from $4\left(H_{\text {lower }}=(I+O) / 2=4\right)$ to $15\left(H_{\text {upper }}=2 I+1=15\right)$, and (4) select an activation function from among four different alternatives (i.e., identity, tanh, logistic, and exponential functions). The default error function $(E)$ and the default supervised learning (i.e., training) algorithm used in the automated MLP neural network search feature of the software are the sum of square errors and BFGS, respectively. The default statistical measure used by the software to select the best five neural networks is the correlation coefficient ( $r$ ). Four statistical measures, the MAE, the RMSE, the MAPE, and the coefficient of determination $\left(R^{2}\right)$, are not available in the software but were computed by the writers to evaluate and compare the performance of the selected MLP neural network.

The network topologies and statistical measures (i.e., $r, R^{2}$, RMSE, MAE, and MAPE) of the best five MLP neural networks developed by the automated network search feature of STATISTICA are presented in Table 4. The statistical measures suggest that Model 2 outperforms the other four MLP neural networks (Table 4). The network topology of Model 2 is presented in Fig. 4. Model 2 has 7 input values in the input layer $(I=7), 12$ neurons in the hidden layer $(H=12)$, and 1 output value in the output layer $(O=1)$ [7-12-1] (Fig. 4). It uses the hyperbolic tangent function for computing activation values of hidden layer neurons and the logistic function for computing the activation value of the neuron located in the output layer (Table 4). Model 2 has the highest correlation coefficients $(r)$ and coefficients of determination $\left(R^{2}\right)$ for both training and testing (Table 4$)$. These coefficients are close to 1 and statistically significant $(p \geq 0.001)$ (Table 4$)$. Furthermore, Model 2 has the lowest error measures (MAE, RMSE, and MAPE) for both training and testing (Table 4). These results jointly point 
Table 4. Network Topologies and Statistical Measures of the Best Five MLP Neural Networks

Network bottomology

Activation function

\begin{tabular}{|c|c|c|c|c|c|c|c|c|}
\hline Model & $\mathrm{I}-\mathrm{H}-0$ & Hidden layer & Output layer & MAE & RMSE & MAPE & $r^{\mathrm{a}}$ & $R^{2^{\mathrm{a}}}$ \\
\hline 1 & $7-12-1$ & Tanh & Logistic & $0.242(0.319)$ & $0.302(0.419)$ & $0.047(6.837)$ & $0.949(0.914)$ & $0.900(0.836)$ \\
\hline 2 & $7-12-1$ & Tanh & Logistic & $0.161(0.235)$ & $0.231(0.283)$ & $3.143(4.546)$ & $0.969(0.963)$ & $0.940(0.927)$ \\
\hline 3 & $7-15-1$ & Tanh & Logistic & $0.246(0.306)$ & $0.308(0.366)$ & $5.003(5.677)$ & $0.946(0.932)$ & $0.895(0.869)$ \\
\hline 4 & $7-13-1$ & Exp & Tanh & $0.192(0.344)$ & $0.253(0.375)$ & $3.781(7.110)$ & $0.963(0.927)$ & $0.928(0.859)$ \\
\hline 5 & $7-15-1$ & Tanh & Tanh & $0.222(0.294)$ & $0.283(0.340)$ & $4.421(5.867)$ & $0.955(0.931)$ & $0.911(0.866)$ \\
\hline
\end{tabular}

${ }^{\mathrm{a}} p \leq 0.001$ and test results are given in parentheses.

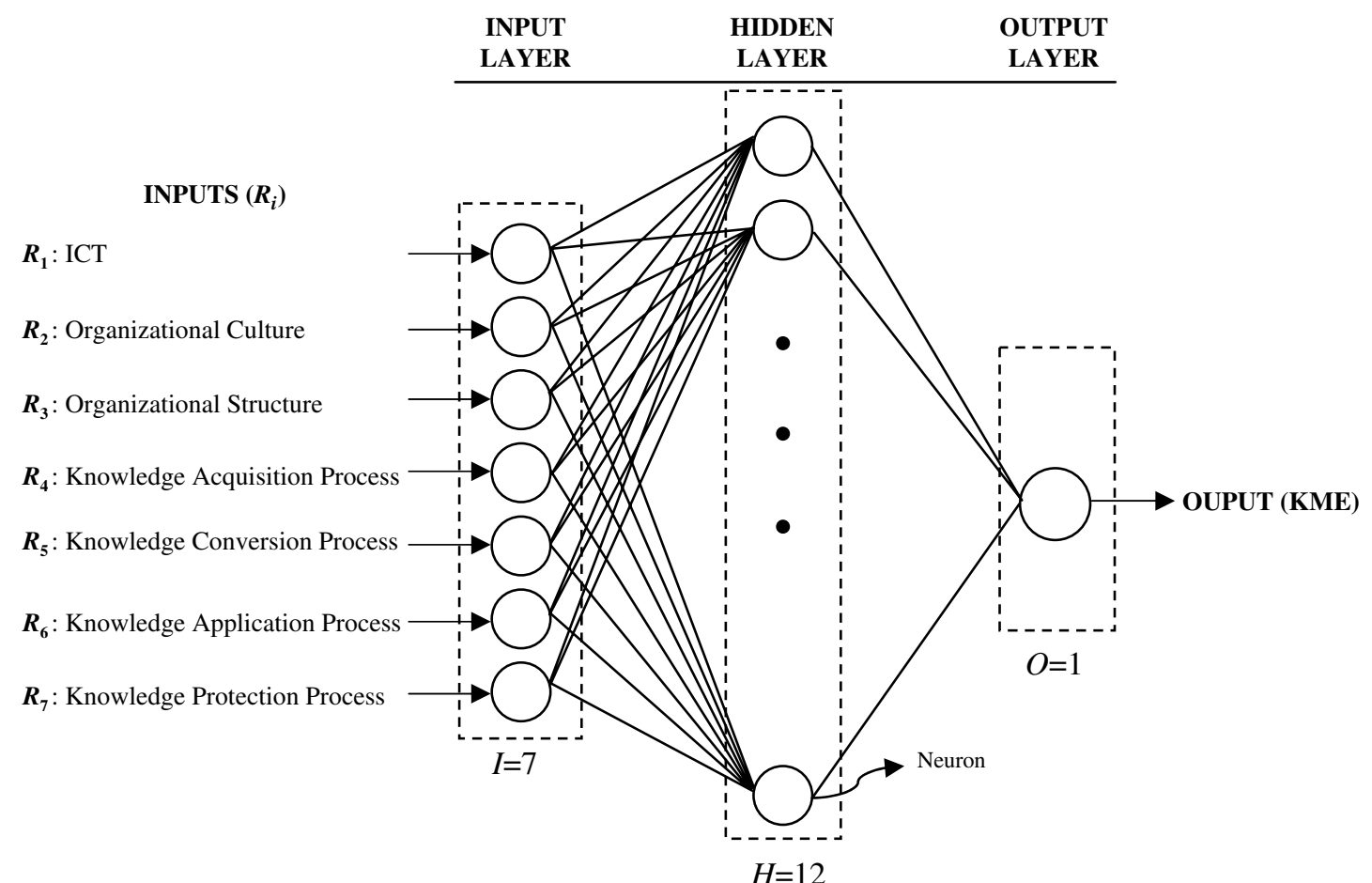

$\boldsymbol{I}$, number of input layer neurons; $\boldsymbol{H}$, number of hidden layer neurons; $\boldsymbol{O}$, number of output layer neurons; $\boldsymbol{R}_{i}$, performance rating of $i$ th knowledge management practice

Fig. 4. Neural network topology for Model $2(7-12-1)$

out that Model 2 has the highest predictive ability and the lowest errors and hence can be used to derive the importance weights of knowledge management practices. Table 5 presents the importance weight $\left(W_{i}\right)$ of each knowledge management practice $\left(C_{i}\right)$ derived by using Eq. (3). It suggests that the most important knowledge management practice for construction firms is their knowledge application process $\left(W_{6}=0.270\right)$, whereas the least important practice is their knowledge acquisition process $\left(W_{4}=0.073\right)$. The mean value of the implicitly derived importance weights (MW) is 0.143 (Table 5).

\section{Constructing an Importance-Comparative Performance Analysis Map for the Case Firm}

A construction firm was selected as the case firm in this study to illustrate the use of the proposed model. The case firm is based in Istanbul, Turkey. It employs 155 full-time personnel. Its turnover was more than $\$ 175$ million in 2009. It generally undertakes infrastructure and general building projects.
The ICPA map for the case firm is presented in Fig. 5. The comparative performance ratios with respect to each knowledge management practice $\left(\mathrm{CPR}_{i}\right)$ of the case firm were calculated by using Eq. (4). Table 5 presents the comparative performance ratios $\left(\mathrm{CPR}_{i}\right)$ for each knowledge management practice of the case firm. The case firm's organizational culture has the highest comparative performance ratio $\left(\mathrm{CPR}_{2}=1.061\right)$, whereas its knowledge conversion has the lowest $\left(\mathrm{CPR}_{5}=0.786\right)$. The $y$-axis of the ICPA map presented in Fig. 5 was divided into two areas by drawing a horizontal line representing a comparative performance ratio of 1 $(\mathrm{CPR}=1)$. The areas above the line represent the case firm's competitive advantages in its knowledge management practices, whereas the areas below the line represent its competitive disadvantages. Similarly, the $x$-axis of ICPA map presented in Fig. 5 was divided into two areas by a vertical line representing the mean of implicitly derived importance weights $(\mathrm{MW}=0.143)$. The knowledge management practice(s) in the areas to the left of this line have relatively low importance for improving the effectiveness of knowledge management, whereas practices in the areas to the 
Table 5. Performance Ratings, Comparative Performance Ratios, and Importance Weights of Knowledge Management Practices

\begin{tabular}{lcccc}
\hline \multirow{4}{*}{$\begin{array}{l}\text { Knowledge } \\
\text { management }\end{array}$} & \multicolumn{2}{c}{ Performance rating } & Industry \\
\cline { 2 - 4 } practice $\left(C_{i}\right)$ & $\begin{array}{c}\text { Case firm } \\
\left(R_{i}\right)\end{array}$ & $\begin{array}{c}\text { average } \\
\left(\mathrm{AvR}_{i}\right)\end{array}$ & $\begin{array}{c}\text { Comparative } \\
\text { performance } \\
\text { ratio }\left(\mathrm{CPR}_{i}\right)\end{array}$ & $\begin{array}{c}\text { Derived } \\
\text { importance } \\
\text { weight }\left(W_{i}\right)^{\text {a }}\end{array}$ \\
\hline$C_{1}$-ICT & 4.363 & 4.941 & 0.883 & 0.122 \\
$C_{2}$-CUL & 6.060 & 5.712 & 1.061 & 0.168 \\
$C_{3}$-STR & 5.714 & 5.789 & 0.987 & 0.195 \\
$C_{4}-\mathrm{ACQ}$ & 5.884 & 5.702 & 1.032 & 0.073 \\
$C_{5}$-CON & 4.219 & 5.368 & 0.786 & 0.098 \\
$C_{6}-\mathrm{APL}$ & 4.780 & 5.604 & 0.853 & 0.270 \\
$C_{7}-\mathrm{PRO}$ & 4.452 & 4.538 & 0.981 & 0.075 \\
Mean & & - & - & 0.143 \\
\hline
\end{tabular}

${ }^{\mathrm{a} O n}$ the basis of MLP neural network-Model 2.

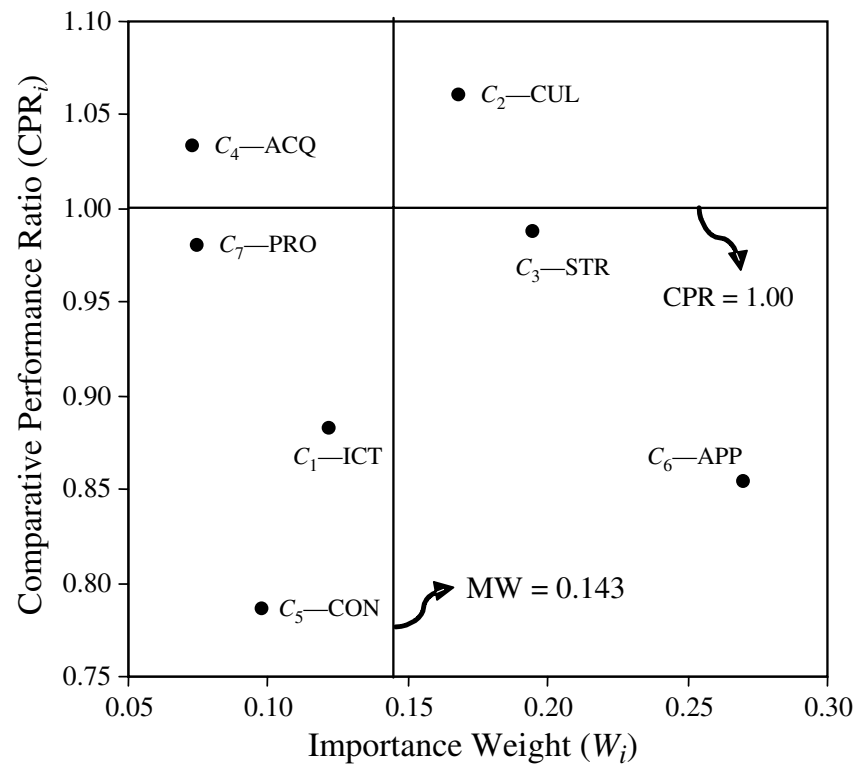

Fig. 5. ICPA map for the case firm

right of this line have relatively high importance for improving the effectiveness of knowledge management.

The visual inspection of the ICPA map of the case firm in Fig. 5 reveals several important issues. First, the case firm performs above industry average on two knowledge management practices. The comparative advantages of the case firm are its organizational culture $\left(\mathrm{CPR}_{2}=1.061\right)$ and its knowledge acquisition process $\left(\mathrm{CPR}_{4}=1.032\right)$. Second, the case firm performs below industry average on five knowledge management practices. Organizational structure $\left(\mathrm{CPR}_{3}=0.987\right)$ and the knowledge protection process $\left(\mathrm{CPR}_{7}=0.981\right)$ are minor comparative disadvantages of the case firm, whereas ICT $\left(\mathrm{CPR}_{1}=0.883\right)$, the knowledge conversion process $\left(\mathrm{CPR}_{5}=0.786\right)$, and the knowledge application process $\left(\mathrm{CPR}_{6}=0.853\right)$ are major comparative disadvantages.

The ICPA map provides several important insights for prioritizing and developing managerial action plans and for improving the knowledge management practices of the case firm. First, the knowledge application process $\left(C_{6}\right)$ and organization structure $\left(C_{3}\right)$ are located in the immediate action quadrant (i.e., SE quadrant). The knowledge application process is a major comparative disadvantage of the case firm $\left(\mathrm{CPR}_{6}=0.853<1\right)$, yet it has the highest importance weight $\left(W_{6}=0.270\right)$. Therefore, the highest priority for immediate managerial action for the case firm is its knowledge application process $\left(C_{6}\right)$. The case firm should seek means to enhance its comparative performance ratio for the knowledge application process. Second, organizational structure $\left(C_{3}\right)$ is a minor comparative disadvantage of the case firm because its comparative performance ratio $\left(\mathrm{CPR}_{3}=0.987\right)$ is slightly smaller than industry average $(\mathrm{CPR}=1)$. But organizational structure has the second highest importance weight $\left(W_{3}=0.195\right)$. Therefore, it has the second highest priority for managerial action. Third, the knowledge conversion process $\left(C_{5}\right)$, ICT $\left(C_{1}\right)$, and knowledge protection $\left(C_{7}\right)$ are located in the SW quadrant. They have relatively lower priority for managerial action despite the fact that the case firm performs poorly on these knowledge management activities. The case firm should however closely monitor its ICT $\left(C_{1}\right)$ because a slight increase in the importance weight of this practice could move it to the $\mathrm{SE}$ quadrant. Fourth, the knowledge acquisition process $\left(C_{4}\right)$ is located in the NW quadrant. It has the second highest comparative performance ratio $\left(\mathrm{CPR}_{4}=1.032\right)$. The case firm's performance rating for the knowledge acquisition process is greater than the average performance rating of all the firms. Yet the knowledge acquisition process has the lowest importance weight $\left(W_{4}=0.073\right)$. It appears that the case firm has overemphasized the knowledge acquisition process. Therefore, the case firm should direct its efforts to knowledge practices that need managerial action, in particular its organizational structure $\left(C_{3}\right)$. Fifth, organizational culture $\left(C_{2}\right)$ is located in the NE quadrant. It has the highest comparative performance ratio $\left(\mathrm{CPR}_{2}=1.061\right)$. It appears that the organizational culture of the case firm creates a supportive environment for its employees to engage in knowledge management activities. Therefore, the case firm should maintain its good performance on this knowledge management practice because it has the third highest importance weight.

A poststudy interview with the three executives of the case study firm was conducted to verify the results of the proposed model. The executives considered whether the proposed model offers a practical and useful procedure to evaluate and, in turn, improve their knowledge management practices. They agreed that the power of the model is its ability (1) to provide a structured approach for understanding and evaluating knowledge management practices and (2) to pinpoint where their strengths and weaknesses lay in knowledge management practices. The executives of the case study firm indicated that they would initiate a managerial improvement plan on the basis of the case study results.

\section{Conclusions and Implications}

The research presented here proposes a model to evaluate the knowledge management practices of construction firms. It builds on concepts set forth in knowledge management models, MLP neural networks, and ICPA maps. The model proposed in this paper has several practical implications for construction firms. First, it is a simple, visual tool that can be easily used by construction company executives. It is capable of providing powerful diagnostic information on construction firms' knowledge management practices. Second, the proposed model can be used by construction firms as an internal performance measurement tool to evaluate their knowledge management practices. Third, the proposed model can guide construction firms in developing priorities for managerial action plans and interventions for knowledge management practices that need immediate improvement, hence assisting construction business executives in pinpointing those areas that need improvement to succeed in the future. Fourth, the proposed model can be used by construction firms to identify areas of wasted effort and/or 
overinvestment because construction firms, like other firms, have limited resources, and the effective and efficient use of resources is the key to outperforming rivals. The proposed model has some academic implications. First, it shows that complex relationships between $\mathrm{KME}$ and knowledge management $(\mathrm{KM})$ practices $\left(C_{i}\right)$ can be identified successfully by using MLP neural networks. Second, the results of the MLP neural network model used to construct the ICPA map indicate that the knowledge application process has the highest relative importance weight. The relatively higher importance of this knowledge management practice can be explained by Grant's (1996) propositions, which state that knowledge has no value for a firm if it is not used in improving the firm's efficiency and/or effectiveness. Yet, more research studies are needed to validate this proposition.

The implications of the proposed model should be evaluated in light of its limitations. First, the primary objective of the study was to develop a model to evaluate the knowledge management practices of construction firms. Therefore, explaining the causal relationship between knowledge management practices and KME is beyond the scope of the research. Second, the proposed model measures the KME of construction firms only from a process perspective. Measuring KME from different perspectives (e.g., financial, market, and customer) and levels (e.g., project and units) can provide richer insights. Third, the derived importance weights of knowledge management practices reflect industry tendencies. It should be noted that benchmarking the knowledge management practices on the basis of industry tendencies is applicable to most of the construction firms but not to all construction firms. Fourth, construction firms operating in the Turkish construction industry can build their own ICPA map by using the implicitly derived importance weights presented in this paper and by answering the questions in the KMB-I questionnaire. However, it must be recognized that implicitly derived importance weights and industry average performance ratings for knowledge management practices can vary from country to country. AEC firms operating in other parts of the world can construct their ICPA maps by deriving importance weights and industry average performance ratings for knowledge management practices in their country.

\section{References}

Alavi, M., Kayworth, T. R., and Leidner, D. E. (2006). "An empirical examination of the influence of organizational culture on knowledge management practices." J. Manage. Inf. Syst., 22(3), 191-224.

Al-Ghassani, A. M., Kamara, J. M., Anumba, C. J., and Carrillo, P. M. (2004). "An innovative approach to identifying knowledge management problems." Eng. Constr. Archit. Manage., 11(5), 349-357.

Arif, M., Egbu, C., Alom, O., and Khalfan, M. (2009). "Measuring knowledge retention: A case study of a construction consultancy in the UAE." Eng. Constr. Archit. Manage., 16(1), 92-108.

Carrillo, P. (2004). "Managing knowledge: Lessons from the oil and gas sector." Constr. Manage. Econ., 22(6), 631-642.

Carrillo, P., and Chinowsky, P. (2006). "Exploiting knowledge management: The engineering and construction perspective." J. Manage. Eng., 22(1), 2-10.

Carrillo, P. M., Robinson, H., Al-Ghassani, A., and Anumba, C. J. (2004). "Knowledge management in UK construction: Strategies, resources and barriers." Proj. Manage. J., 35(1), 46-56.

Chen, M. Y., and Chen, A. P. (2006). "Knowledge management performance evaluation: A decade of review from 1995 to 2004." J. Inf. Sci., 32(1), 17-38.

Chen, M. Y., Huang, M. J., and Cheng, Y. C. (2009). "Measuring knowledge management performance using a competitive perspective." Expert Syst. Appl., 36(4), 8449-8459.

Chinowsky, P., and Carrillo, P. (2008). "A strategic argument for knowledge management." Proc., Leadership and Management in Construction
(LEAD), South Lake Tahoe, CA, 1-11.

Chuang, S. H. (2004). "A resource-based perspective on knowledge management capability and competitive advantage." Expert Syst. Appl., 27(3), 459-465.

Cortes, E. C., Saez, P. Z., and Ortega, E. P. (2007). "Organizational structure features supporting knowledge management process." J. Knowl. Manage., 11(4), 45-47.

Daft, R. L. (1995). Organization theory and design, West, St. Paul, MN.

Deng, W. J., and Pei, W. (2009). "Fuzzy neural network based importance and performance analysis for determining critical service attributes." Expert Syst. Appl., 36(2), 3774-3784.

Egbu, C. O., and Botterill, K. (2002). "Information technologies for knowledge management: Their usage and effectiveness." J. Inf. Technol. Constr., 7, 125-137.

Fong, P. S. W., and Chu, L. (2006). "Exploratory study of knowledge sharing in contracting companies." J. Constr. Eng. Manage., 132(9), 928-939.

Fong, P. S. W., and Kwok, C. W. (2009). "Organizational culture and knowledge management success at project and organizational levels in contracting firms." J. Constr. Eng. Manage., 135(12), 1348-1356.

Garver, M. S. (2003). "Best practices in identifying customer driven improvement opportunities." Ind. Mark. Manage., 32(6), 455-466.

Ghosh, B., and Scott, J. E. (2006). "Effective knowledge management systems for a clinical nursing setting." Inf. Syst. Manage., 24(1), 73-84.

Gold, A. H., Malhotra, A., and Segars, A. H. (2001). "Knowledge management: An organizational capabilities perspective." J. Manage. Inf. Syst., 18(1), 185-214.

Grant, R. M. (1996). "Toward a knowledge-based theory of the firm." Strategic Manage. J., 17(Special Issue: Knowledge and the Firm, Winter), 109-122.

Hansen, M. T., Norhia, N., and Tierney, T. (1999). "What's your strategy for managing knowledge?" Harv. Bus. Rev., 77(2), 106-116.

Haykin, S. (1999). Neural networks: A comprehensive foundation, Pearson, New York.

Hecht-Nelson, R. (1987). "Kolmogorov's mapping neural network existence theorem." Proc., 1st IEEE Annual Conf. on Neural Networks, IEEE, Piscataway, NJ.

Hsieh, P. J., Lin, B., and Lin, C. (2009). "The construction and application of knowledge navigator model." Expert Syst. Appl., 36(2), 4087-4100.

Huber, G. P. (2001). “Transfer of knowledge management systems.” Eur. J. Inf. Syst., 10(2), 72-79.

Inkpen, A. C. (1996). "Creating knowledge through collaboration." Calif. Manage. Rev., 39(1), 123-140.

Javernick-Will, A., and Levitt, R. E. (2010). "Mobilizing institutional knowledge for international projects." J. Constr. Eng. Manage., 136(4), 430-441.

Kamara, J. M., Anumba, C. J., and Carrillo, P. M. (2002). "A CLEVER approach to selecting a knowledge management strategy." Int. J. Proj. Manage., 20(3), 205-211.

Kivrak, S., Gokhan, A., Dikmen, I., and Birgonul, T. (2008). "Capturing knowledge in construction projects: Knowledge platform for contractors." J. Manage. Eng., 24(2), 87-95.

Kululanga, G. K., and McCaffer, R. (2001). "Measuring knowledge management for construction organizations." Eng. Construct. Archit. Manage., 8(6), 346-354.

Lawrence, J., and Fredrickson, J. (1998). Brainmaker user's guide and reference manual, California Scientific Software, Nevada City, CA.

Lee, H., and Choi, B. (2003). "Knowledge management enablers, processes and organizational knowledge." J. Manage. Inf. Syst., 20(1), $179-228$.

Lin, H. F. (2007). "A stage model of knowledge management: an empirical investigation of process and effectiveness." J. Inf. Sci., 33(6), 643-659.

Marr, B., and Spender, J. C. (2004). "Measuring knowledge assetsImplications of the knowledge economy for performance measurement." Meas. Bus. Excell., 8(1), 18-27.

Martilla, J., and James, J. C. (1997). "Importance—performance analysis." J. Mark., 41(1), 77-79.

Nahapiet, J., and Ghoshal, S. (1998). "Social capital, intellectual capital, and the organizational advantage." Acad. Manage. Rev., 23(2), 242-266. 
Nonaka, I., and Takeuchi, H. (1994). The knowledge-creating company, Oxford University, UK.

Nunnally, J. C. (1978). Psychometric theory, 2nd Ed., McGraw-Hill, New York.

Pennings, J. M. (1992). "Structural contingency theory." Research in organizational behavior, B. Staw and I. L. Cummings, eds., JAI, Greenwich, CT, 267-309.

Robinson, H. S., Carrillo, P. M., Anumba, C. J., and Al-Ghassani, A. M. (2004). "Developing a business case for knowledge management: The IMPaKT approach.” Constr. Manage. Econ., 22(7), 733-743.

Robinson, H., Carrillo, P. M., Anumba, C. J., and Al-Ghassani, A. M. (2005). "Knowledge management practices in large construction organizations." Eng. Constr. Archit. Manage., 12(5), 431-445.

Russell, S. J., and Norvig, P. (2003). Artificial intelligence, Prentice Hall, NJ.

Sarrafzadeh, M., Martin, B., and Hazeri, A. (2006). "LIS professionals and knowledge management." Lib. Manage., 27(9), 621-635.

Schein, E. H. (1985). Organizational culture and leadership, Jossey-Bass, San Francisco.

Spender, J. C. (1996). "Making knowledge the basis of a dynamic theory of the firm." Strateg. Manage. J., 17(Special Issue: Knowledge and the Firm, Winter), 45-62.

Wen, Y. F. (2009). "An effectiveness measurement model for knowledge management." Knowl. Base. Syst., 22(5), 363-367.

Wiig, K. (1993). Knowledge management foundations, Schema, Arlington, TX.

Wiig, K. M. (1997). "Knowledge management: Where did it come from and where will it go?" Expert Syst. Appl., 13(1), 1-14.

Yu, W., Chang, P., Yao, S., and Liu, S. (2009). "KVAM: Model for measuring knowledge management performance of engineering community of practice." Constr. Manage. Econ., 27(8), 733-747. 